\title{
POTRET FULL DAYCARE SEBAGAI SOLUSI PENGASUHAN ANAK BAGI ORANG TUA PERKERJA
}

\section{(Studi pada TPA Pertiwi Metro)}

\author{
Wellfarina Hamer
}

Institut Agama Islam Negeri Metro

E-Mail:wellfarinahamer@metrouniv.ac.id

Tubagus Ali Rachman

Institut Agama Islam Negeri Metro

E-Mail: tubagus.ali.rachman@metrouniv.ac.id

\section{Anita Lisdiana}

Institut Agama Islam Negeri Metro

E-Mail: anitalisdiana@metrouniv.ac.id

\section{Wardani}

Institut Agama Islam Negeri Metro

E-Mail:wardani@metrouniv.ac.oid

\section{Karsiwan}

Institut Agama Islam Negeri Metro

E-Mail:karsiwan@metrouniv.ac.id

\section{Atik Purwasih}

Institut Agama Islam Negeri Metro

E-Mail: atik.purwasih5@gmail.com

Tapis : Jurnal Penelitian Ilmiah

Website: http://e-journal.metrouniv.ac.id/index.php/tapis/index

DOI: $\underline{\text { https://doi.org/10.32332/tapis.v4i1.1955 }}$

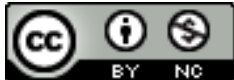

This article is distributed under the terms of the Creative Commons Attribution-NonCommercial 4.0 International License

\begin{abstract}
Children are priceless gifts, a great mandate that God entrusts to every parent. Parenting and environments greatly affect emotional-social intelligence and children's character. For working parents, efforts to meet the needs of children certainly have not been done optimally. For this reason, there are alternatives for working parents to continue to be able to provide rights and fulfillment of children's needs, namely by utilizing full daycare services where children are kept for a full day at the TPA (Child Care Park) until the parents have finished working. This study aims to describe the implementation of full daycare in one of the TPAs in Metro City. How is the implementation of the landfill in terms of caring programs, education, nutrition, and health? Moreover,
\end{abstract}


human resources were to be being a problem. The subject of this research is the TPA Pertiwi Metro. The method used in this research is descriptive qualitative. Data collection techniques using interviews, observation, and documentation on the principal, teachers, and parents of students. Data validity is done by triangulation of sources. From this research, it is known that TPA Pertiwi Metro excels in creating healthy, child-friendly, character-based, environmentally-based religious faith and diversity so that children still get a good education even though their parents work.

Key words: Working Parents, Full Daycare, Parenting

\begin{abstract}
Abstrak
Anak adalah karunia yang tidak ternilai harganya, sebuah amanah besar yang Tuhan titipkan pada setiap orangtua. Pola asuh orang tua dan lingkungan sekitar sangat mempengaruhi kecerdasan sosial emosional dan karakter anak. Bagi orang tua yang bekerja, upaya pemenuhan kebutuhan anak tentu belum dilakukan secara optimal. Untuk itu terdapat alternatif bagi orang tua yang bekerja agar tetap dapat memberikan hak-hak dan pemenuhan kebutuhan anak yaitu dengan memanfaatkan pelayanan full day care dimana anak selama seharian penuh dititipkan di TPA (Taman Penitipan Anak) hingga orang tua selesai bekerja. Penelitian ini bertujuan untuk menggambarkan pelaksanaan full day care yang ada di salah satu TPA yang ada di Kota Metro. Bagaimana pelaksanaan TPA dari segi program perawatan/pengasuhan, pendidikan, gizi dan kesehatan, sumber daya manusia juga kendala yang dihadapi. Subjek penelitian ini adalah TPA Pertiwi Metro. Metode yang digunakan dalam penelitian ini adalah deskriptif kualitatif. Teknik Pengumpulan data menggunakan wawancara, observasi, dan dokumentasi pada kepala sekolah, guru, serta orang tua siswa. Keabsahan data dilakukan dengan cara triangulasi sumber. Dari penelitian tersebut diketahui bahwa TPA Pertiwi Metro unggul dalam mewujudkan sekolah yang sehat, ramah anak, berkarakter, beriman taqwa berbasis lingkungan dan kebhinekaan sehingga anak tetap mendapatkan pendidikan yang baik meskipun orang tuanya bekerja.
\end{abstract}

Kata Kunci: Orang Tua Karir, Full Daycare, Pengasuhan Anak

\title{
A. PENDAHULUAN
}

Pendidikan anak sangat ditentukan oleh pola asuh orang tuanya, orang tua dituntut untuk membersamai dalam setiap tahapan tumbuh kembang anak- anaknya, memerhatikan asupan gizi yang baik juga perkembangan sosial emosionalnya. Namun tidak semua orang tua 
memiliki waktu yang penuh untuk mendampingi tumbuh kembang putera/puterinya dikarenakan kewajiban yang menuntutnya untuk bekerja atau berkarir di luar rumah. Tidak ada orang tua mana pun yang dengan sengaja mau meninggalkan putera/ puterinya dan menyerahkan pengasuhan pada oranglain, namun berbagai masalah muncul yang biasanya didasari karena faktor ekonomi, orang tua berkewajiban memenuhi segala kebutuhan keluarganya.

Semakin tingginya tuntutan hidup pada era digital saat ini mengharuskan orang tua harus bekerja keras dalam memenuhi kebutuhan hidupnya, baik itu kebutuhan primer, sekunder maupun kebutuhan seharihari lainnya. Ditengah tuntutan kebutuhan yang semakin banyak harus dipenuhi dirasa bukan zamannya lagi pada masa kini hanya laki- laki yang berperan untuk mencari nafkah. Saat ini Kesempatan bagi perempuan untuk bekerja juga semakin terbuka lebar sehingga memfasilitasi keinginan perempuan untuk mengambil peran dalam memenuhi kebutuhan keluarganya, atau dengan alasan lain yaitu ingin menjadi perempuan yang mandiri, ingin mengaktualisasikan dirinya sebagai perempuan yang memiliki intelektual tinggi, atau hanya untuk melawan stigma yang saat ini masih menyudutkan peran "Ibu rumah tangga" sebagai kasta yang rendah. Yang semula perempuan hanya mengurusi pekerjaan domestik rumah tangga kini dengan berbagai kemudahan akses perempuan dengan mudah memasuki ranah publik untuk mendapatkan penghasilan tambahan.

Orang tua yang berkarir dihadapkan pada dilema tentang pengasuhan buah hatinya terutama yang memiliki anak usia balita, tentu konsekuensinya adalah dirinya mau tidak mau harus meninggalkan sebagian perannya sebagai pendidik dan pengasuh utama dari anak anaknya, terutama bila anaknya yang masih berusia balita. Sebagian orang tua ada yang menyerahkan pengasuhan pada asisten rumah tangga, namun kita semua tau bilamana pendidikan asisten rumah tangga itu relative rendah maka hal ini hanya bersifat mengawasi anak bukan mendidik¹.

\footnotetext{
1 Supsiloani Supsiloani Supsiloani, Puspitawati Puspitawati Puspitawati, and Noviy Hasanah, “Eksistensi Taman Penitipan Anak dan Manfaatnya bagi Ibu
} 
Ada pula beberapa yayasan yang menawarkan jasa baby sitter bersertifikasi yang dipersiapkan untuk mengawasi, menjaga dan mengasuh anak usia balita, tentu ini menjadi kabar baik bagi orang tua yang bekerja dalam memilih asisten rumah tangga untuk mengasuh anak yang masih usia balita asalkan sanggup membayar biaya yang tidak sedikit.

Sementara masa balita adalah merupakan masa yang sangat penting bagi perkembangan anak. Anak usia balita adalah anak yang masih berada pada tahap pra-sekolah dengan usia 0- 5 tahun. Biasanya mereka tetap tinggal dirumah atau mengikuti kegiatan dilembaga pendidikan prasekolah seperti taman kanak- kanak, kelompok bermain dan taman penitipan anak. Pada masa ini anak perlu mendapatkan pendampingan yang baik bagi orang tuanya maupun bagi guru disekolah, hal ini karena masa lima tahun pertama usia anak adalah masa kritis yang juga merupakan masa yang menjadi basis, landasan, dan fondasi berbagai aspek perkembangan. Dikatakan golden age karena masamasa di mana kemampuan otak untuk menyerap informasi sangat tinggi, apapun informasi yang diberikan akan berdampak kuat bagi anak pada masa- masa yang akan datang.

Maria Montessori 2, seorang tokoh pendidikan anak usia dini terkenal, menyatakan bahwa pada balita adalah masa keemasan yang merupakan masa dimana anak mulai peka/sensitive menerima berbagai rangsangan. Selama masa periode sensitif inilah, anak begitu mudah menerima stimulus-stimulus dari lingkungannya. Usia emas perkembangan anak merupakan masa dimana anak mulai peka untuk menerima berbagai stimulasi dan berbagai upaya pendidikan dari lingkungannya baik disengaja maupun tidak disengaja. Semua masa adalah penting akan tetapi

Rumah Tangga yang Bekerja (Studi Kasus di TPA Dharma Asih Kota Medan)," JUPIIS: JURNAL PENDIDIKAN ILMU-ILMU SOSIAL 7, no. 2 (2015): 119-24, https://doi.org/10.24114/jupiis.v7i2.3117.

2 Maria Montessori, Rahasia Masa Kanak-Kanak, trans. Ahmad Lintang (Yogyakarta: Pustaka Pelajar, 2016). 
pengalaman pertama terjadi pada masa balita, pengalaman pertama itu akan terekam kuat di alam bawah sadar mereka. ${ }^{3}$

Pada masa anak berusia 0 sampai dengan 5 tahun merupakan masa perkembangan otak. Pada usia 0 sampai 5 tahun adalah masa kritis pada anak karena manusia memiliki 100 neuron untuk menyalurkan pesan / komunikasi setiap aktivitas ketika lahir. Neuron ini akan berkembang lebih dari $20 \%$ jika dirangsang dengan pendidikan dan pengetahuan dan merupakan masa untuk mulai mengenal sosialisasi (sekolah, kelompok), menjelajah, bermain, meniru, dan kreatif. ${ }^{4}$

Lain dari itu yang harus lebih diperhatikan dalam pendidikan anak adalah bagaimana memenuhi apa yang menjadi kebutuhan dasar anak. Abraham maslow 5 yang mempopulerkan teori hierarki kebutuhan manusia atau biasa dipahami sebagai tangga yang menggambarkan tingkat kebutuhan. Terdapat lima tingkat kebutuhan dasar, yaitu: kebutuhan fisiologis, kebutuhan akan rasa aman, kebutuhan akan rasa memiliki dan kasih sayang, kebutuhan akan penghargaan dan kebutuhan akan aktualisasi diri.

\section{Gambar 1. Teori Hierarki Kebutuhan Maslow}

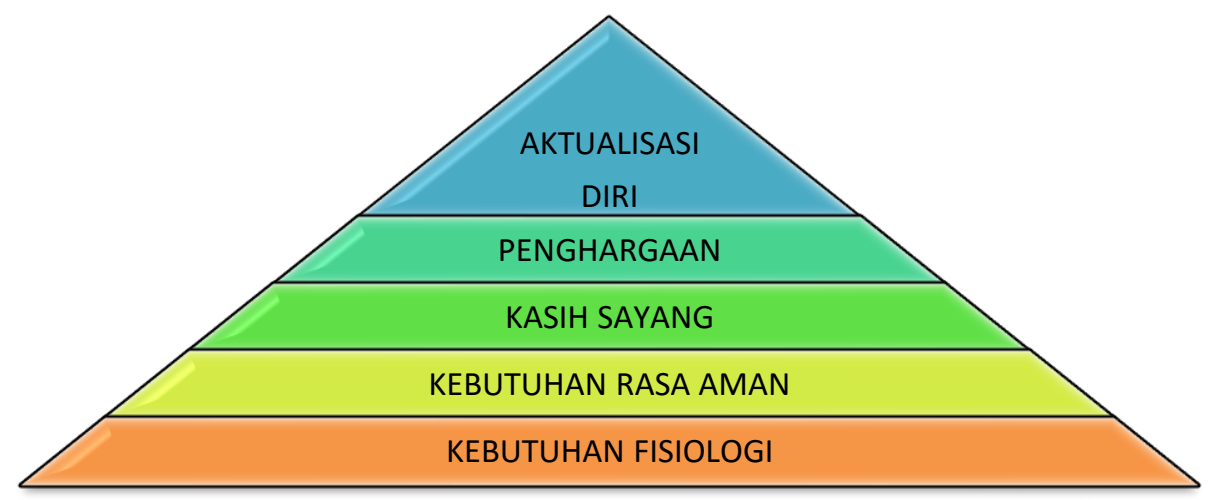

3 "The Golden Age | SpringerLink," accessed April 27, 2020, https://link.springer.com/chapter/10.1007\%2F978-3-319-04840-6_5.

4 Farida Mayar, "Perkembangan Sosial Anak Usia Dini sebagai Bibit untuk Masa Depan Bangsa," Al-Ta lim Journal 20, no. 3 (November 21, 2013): 459-64, https://doi.org/10.15548/jt.v20i3.43.

${ }^{5}$ Abraham MaslowLahir1 April 1908Brooklyn et al., "Abraham Maslow Wikipedia bahasa Indonesia, ensiklopedia bebas," accessed April 27, 2020, https://id.wikipedia.org/wiki/Abraham_Maslow. 
Hal-hal tersebut diatas ini perlu diketahui untuk pembelajaran dan pendampingan tumbuh kembang anak. Sangat penting bagi orang tua dan pemerhati pendidikan memberikan perhatian, rasa aman, kasih sayang, penghargaan dan kesempatan anak mengaktualisasi dirinya yang sesuai dengan kebutuhan dasarnya.

TPA Pertiwi adalah salah satu tempat di Kota Metro yang memberikan layanan full daycare yang ditawarkan sebagai pilihan alternative bagi orang tua yang hendak menitipkan buah hatinya selama bekerja. Tahun 2019 TPA Pertiwi berhasil meraih juara 1 (satu) sekolah berkarakter tingkat nasional dengan mengusung visi “Mewujudkan Sekolah Ramah Anak, Berkarakter, Beriman Taqwa Berbasis Lingkungan dan Kebhinekaan". Berlokasi di pusat Kota Metro dengan bangunan sekolah yang luas, lingkungan yang asri serta beragam fasilitas penunjang juga tersedia disini seperti taman bermain anak, kolam renang, mushola juga taman TOGA (tanaman obat keluarga) dan yang semakin menarik adalah biaya penitipan yang relative terjangkau.

Alasan itulah yang mendasari penulis melakukan penelitian pada TPA Pertiwi Metro untuk melihat lebih dalam seperti apa kegiatan anakanak disana, bagaimana pendampingan guru juga keterlibatan orang tua dan apakah layanan full daycare disini mampu memenuhi kebutuhan anakanak balita sehingga dapat menjadi solusi bagi orang tua yang bekerja.

\section{B. KAJIAN TEORI}

\section{Full Daycare}

Full daycare atau yang biasa dikenal dengan sebutan TPA (Taman Penitipan Anak) adalah tempat dimana orang tua bisa menitipkan anak balita sepeninggalnya bekerja, biasanya TPA atau full daycare ini menyatu dengan taman kanak- kanak. Bila di taman kanak- kanak biasanya anak hanya bersekolah dari pagi hingga siang sedangkan pada TPA anak dititipkan disana dari pagi dan dijemput di sore hari ketika orang tuanya pulang bekerja. 
Menurut Patmonodewo 6 Daycare adalah salah satu sarana pengasuhan anak dalam kelompok, biasanya dilakukan pada saat jam kerja. Daycare adalah upaya untuk mengasuh anak-anak yang kurang dapat menerima asuhan orang tua secara lengkap, bukan untuk menggantikan tugas orang tua dalam mengasuh anak.

Prinsip-Prinsip Penyelenggaraan Full Daycare (TPA) Untuk mendukung mewujudkan anak usia balita yang berkualitas, maju, mandiri, demokrasi, dan berprestasi, maka prinsip filsafat pendidikan di TPA dapat dirumuskan menjadi: Tempa, Asah, Asih dan Asuh.7 Anak yang dititipkan di TPA adalah anak balita dengan rentang usia 0- 5 tahun yang mana masih sangat membutuhkan perhatian dan pendampingan orang dewasa untuk mengoptimalkan setiap tahapan tumbuh kambangnya.

2. Tahapan Pertumbuhan dan Perkembangan Anak Usia Balita

a) Perkembangan fisik pada anak balita

Perkembangan fisik anak usia balita terjadi sangat mengagumkan dan sangat berkembang keterampilan fisiknya, berkembangnya eksplorasi terhadap lingkungan tanpa bantuan orang tuanya. Perkembangan sistem syaraf pusat memberikan kesiapan pada anak untuk lebih meningkatkan pemahaman dan penguasaannnya terhadap tubuhnya.

a. Tinggi: Pertambahan tinggi badan setiap tahunnya rata-rata tiga inci;

b. Berat: Pertambahan berat badan setiap tahunnya rata-rata tiga sampai lima pon;

c. Perbandingan tubuh: Penampilan bayi tidak tampak lagi. Wajah tetap kecil tetapi dagu tampak jelas dan leher lebih memanjang. Gumpalan tubuh berkurang dan tubuh cenderung berbentuk kerucut, dengan perut yang rata, dan dada yang lebih bidang, bahu lebih luas dan persegi, lengan dan kaki lebih panjang dan lurus, tangan dan kaki lebih besar;

\footnotetext{
${ }^{6}$ Patmonodewo Soenarti, Pendidikan Anak Prasekolah (Jakarta: Rineka Cipta, 2003).

7 “Norma, Standar, Prosedur, Dan Kriteria (NSPK) Petunjuk Teknis Penyelanggaraan Taman Penitipan Anak," 2013.
} 
d. Postur tubuh: Perbedaan dalam tubuh pertama kali tampak jelas pada awal masa kanak-kanak, ada yang postur tubuhnya gemuk lembek (endomorfik), ada yang kuat berotot (mesomorfik), ada yang relatif kurus (ektomorfik);

e. Tulang dan otot: Tingkat pergeseran otot bervariasi pada bagian tubuh mengikuti hukum perkembangan arah. Otot menjadi lebih besar, berat dan kuat, sehingga anak tampak lebih kurus meskipun beratnya bertambah;

f. Lemak: Anak yang cenderung bertubuh endomorfik lebih banyak jaringan lemaknya dari pada jaringan ototnya sedangkan mesomorfik sebaliknya dan yang bertubuh ektomorfik mempunyai otot yang kecil dan sedikit jaringan lemak. ${ }^{8}$

\section{b) Pekembangan Kognitif}

Perkembangan anak usia dini meliputi perkembangan kemampuan kognitifnya. kemampuan kognitif ini barkaitan dengan daya ingat, kemampuan menganalisa maupun kemampuannya memecahkan masalah. Anak usia balita adalah peneliti kecil, mereka aktif melakukan percobaan dan menganalisa apa yang ada di sekelilingnya. Di sini dukungan lingkungan untuk menunjang perkembangan kognitif anak sangat diperlukan. Interaksi yang sehat antara anak dan lingkungan dapat mengoptimalkan perkembangan kognitifnya. ${ }^{9}$

\section{c) Perkembangan Mental dan Sosial}

Perkembangan mental dan sosial anak sangat dipengaruhi oleh proses perlakuan atau bimbingan orang tua terhadap anak dalam mengenalkan berbagai aspek kehidupan sosial atau norma dalam masyarakat. Proses ini biasanya disebut dengan sosialisasi. Tingkah laku sosialisasi adalah sesuatu yang dipelajari, bukan sekedar hasil dari kematangan. Perkembangan sosial anak diperoleh selain dari proses

\footnotetext{
1996).

${ }^{8}$ Elizabeth B. Hurlock, Psikologi Perkembangan, 5th ed. (Jakarta: Erlangga,

${ }^{9}$ Erna Setianingrum, Buku Ajar Tumbuh Kembang Anak Usia 0-12 Tahun (Sidoarjo: Indomedia Pustaka, 2017).
} 
kematangan juga melalui kesempatan belajar dari respons terhadap tingkah laku. ${ }^{10}$

Pada TPA Pertiwi terdapat 24 anak, 12 anak perempuan dan 12 anak laki- laki dengan rentang usia 1-3 tahun,dari mayoritas orang tua yang bekerja sebagai Pegawai Negeri Sipil di Kota Metro. Sejak pukul 07.00 pagi sampai pukul 16.00 sore selama lebih kurang 9 jam anak- anak dididik oleh tim pengajar sebanyak 8 orang guru perempuan lulusan sarjana Pendidikan Anak Usia Dini juga didampingi oleh seorang ahli gizi serta 2 orang tenaga kesehatan. Semuanya bersinergi dalam mendidik dan mengoptimalkan tumbuh kembang anak.

\section{METODE PENELITIAN}

Metode yang di gunakan dalam penelitian ini adalah deskriptif kualitatif, penelitian ini dilakukan di TPA Pertiwi Metro. Dalam hal ini peneliti berperan sebagai instrumen kunci yang hasilnya nanti lebih menekankan makna11.

Teknik pengumpulan data berupa wawancara, observasi juga dokumentasi dan untuk menguji keabsahan data peneliti menggunakan triangulasi waktu. Waktu juga sering memengaruhi kredibilitas data, data yang dikumpulkan dengan teknik wawancara dipagi hari pada saat narasumber masih segar, belum banyak masalah tentu dirasa akan memberikan data yang lebih valid sehingga lebih kredibel. Untuk itu, dalam rangka pengujian kredibilitas data dapat dilakukan dengan cara melakukan pengecekan dengan wawancara, observasi, atau teknik lain dalam waktu dan situasi yang berbeda.

Sumber data dalam penelitian ini adalah kepala sekolah, guru dan beberapa orang tua/ wali siswa. pengumpulan data dilakukan secara teliti sehingga data yang di peroleh menjadi valid dengan memerhatikan kecukupan bahan referensi, dan member cek.

${ }^{10}$ Femmi Nurmalitasari, "Perkembangan Sosial Emosi pada Anak Usia Prasekolah," Buletin Psikologi 23, no. 2 (December 1, 2015): 103-111-111, https://doi.org/10.22146/bpsi.10567. 2012).

${ }^{11}$ Sugiono, Metode Penelitian Kuantitatif Dan Kualitatif (Bandung: Alfabeta, 


\section{HASIL PENELITIAN}

Pengembangan karakter anak di TPA Pertiwi Metro berfokus pada strategi holistic integrative yang direncanakan secara kolegial, sistematis dan diterapkan secara sistemik untuk mengoptimalkan potensi tumbuh kembang anak secara optimal agar kelak menjadi anak yang berkualitas dan berdaya saing dimasa depan. Undang- undang no 23 tahun 2002 pasal 4 tentang perlindungan anak, mengamanatkan bahwa anak mempunyai hak untuk dapat hidup tumbuh, berkembang dan berpartisipasi secara wajar sesuai harkat dan martabat kemanusiaan serta mendapatkan perlindungan dari kekerasan dan diskriminasi.

Dalam mewujudkan sekolah ramah anak, maka layanan pendidikan anak usia dini harus dapat menciptakan suasana yang kondusif agar anak didik merasa nyaman dan dapat mengekspresikan potensinya. Untuk menciptakan lingkungan kondusif yang ramah anak disini ada beberapa aspek yang sangat diperhatikan yaitu perencanaan program yang sesuai dengan tahap pertumbuhan dan perkembangan anak didik. Melalui visi TPA Pertiwi Metro “Mewujudkan Sekolah Ramah Anak, Berkarakter, Beriman Taqwa Berbasis Lingkungan dan Kebhinekaan" sekolah ini terus bertekad mewujudkan mimpinya menyiapkan generasi yang sehat dan cerdas melalui manajemen berbasis sekolah yang terukur, transparan, akuntable, partisipatif dan sustainable.

Pengumpulan data melalui teknik wawancara, observasi dan dokumentasi dari kepala sekolah, guru dan juga orang tua siswa maka diperoleh beberapa hal kegiatan dan pendampingan orang tua dan pihak sekolah dalam mengoptimalkan tumbuh kembang anak sebagai berikut:

\section{a. Pendampingan Oleh Guru di TPA Pertiwi Metro}

Kesabaran menjadi kunci utama yang harus dimiliki guru dalam mendampingi anak- anak, disini ada beberapa hal yang dilakukan guru di TPA Pertiwi Metro dalam mengajarkan, mengoptimalkan tumbuh kembangnya serta menanamkan pendidikan karakter yang baik bagi anakanak antaranya:

1. Menyambut kedatangan anak 
Sebelum anak- anak datang guru dan kepala sekolah sudah menyambut anak- anak di depan pintu gerbang sekolah, hal ini dilakukan untuk menjalin kedekatan antara guru dan siswa juga guru dengan orang tua. Bersalaman dan saling menanyakan kabar juga rutin dilakukan, itulah yang menjadikan kepala sekolah, guru dan anak menjadi sangat dekat sehingga anak- anak merasa nyaman di sekolah yang menjadi rumah kedua bagi mereka.

2. Memberi teladan yang baik

Satu tindakan lebih baik dari seribu kata- kata, inilah yang menjadi prinsip guru- guru di TPA Pertiwi Metro dalam mendidik anak- anak. Guru memberi contoh bagaimana bertutur kata yang baik, bagaimana menyayangi sesama teman, juga mengajarkan tanggung jawab misalnya dengan bersama- sama merapikan mainan setelah selesai bermain, membuang sampah pada tempatnya, mengajarkan bagaimana meminta maaf ketika melakukan kesalahan, meminta tolong ketika membutuhkan bantuan seseorang dan berterimakasih ketika mendapatkan sesuatu dari oranglain serta menumbuhkan rasa percaya diri anak dengan mengajak anak terlibat dalam kegiatankegiatan sekolah sehingga anak terbiasa untuk tampil di depan umum, rasa percaya diri inilah yang akan memengaruhi aspek perkembangan lainnya di kemudian hari.

3. Mewujudkan sekolah yang ramah anak, bersih, sehat, aman dan nyaman

Anak- anak di bekali pengetahuan tentang hidup bersih, kegiatan berkebun, pentingnya menjaga kesehatan juga disini tersedia cathring dengan menu 4 bintang yang lezat, kemudian setiap 1 bulan sekali ada program baby massage untuk anak- anak TPA.

4. Mewujudkan penguatan pendidikan karakter bagi anak dan dalam kehidupan sekolah maupun kehidupan sehari- hari melibatkan anak dalam kegiatan pentas menari, taekwondo/karate, renang, mengaji, kegiatan bermain dan belajar didalam kelas juga berkebun, interaksi antar teman dan interaksi dengan para pendidik 
membuat anak belajar tentang bagaimana sikap saling menghargai, menyayangi, berbagi, mencintai lingkungan dan bertanggung jawab atas apa yang diperbuatnya.

5. Menumbuhkan cinta tanah air dengan berbagai keragaman budaya Anak- anak disini mulai dikenalkan bagaimana menjaga lingkungan, diajarkan tarian tarian tradisional daerah, menyanyikan lagu Indonesia Raya juga semangat nasionalisme melalui kegiatan upacara bendera.

\section{b. Pendampingan Kepala Sekolah di TPA Pertiwi Metro}

Keberhasilan sebuah lembaga pendidikan sangat ditentukan oleh peran kepemimpinan kepala sekolah. Karena kepala sekolah sebagai pemimpin di lembaganya, maka kepala sekolah harus mampu membawa lembaga ke arah tercapainya tujuan yang telah di tentukan. Kepala sekolah harus mampu melihat adanya perubahan terhadap regulasi pendidikan dan kehidupan globalisasi. Kepemimpinan kepala sekolah sangat menunjang akan tercapainya pengelolaan sekolah yang efektif dan efisien. Untuk menciptakan sekolah yang efektif dan efisien, kepala sekolah sebagai manajer pendidikan di tingkatan sekolah dan ujung tombak utama dalam mengelola pendidikan diharapkan mampu memegang tugas dan bertanggung jawab memegang peran aktif dalam memajukan sekolah / lembaga pendidikan. Pemimpin yang baik adalah pemimpin yang memiliki visi dan misi yang jelas, berkarakter dan memiliki kecerdasan intelektual, emosional dan spiritual yang baik ${ }^{12}$.

TPA Pertiwi metro dikepalai oleh Ibu Astutiningsih, M.Pd. beliau seorang pemimpin yang hebat, memiliki kepribadian yang baik sehingga mampu membawa TPA Pertiwi menjadi juara 1 pada lomba Sekolah TPA berkarakter tingkat nasional. Berkomitmen untuk tetap menjadikan TPA Pertiwi menjadi sekolah unggul di kota Metro maka yang dilakukan dalam mengoptimalkan perkembangan anak melalui program- program yang

${ }^{12}$ Ary Ginanjar Agustian, ESQ (Emotional Spiritual Quotient: Rahasia Sukses Membangun Kecerdasan Emosi Dan Spiritual (Jakarta: Arga, 2005). 
diberlakukan disekolah yaitu menjunjung tinggi nilai- nilai "BAHAGIA" yaitu:

1. Bermanfaat dan berguna untuk oranglain;

2. Amanah, kerja keras, tanggungjawab dan ikhlas dalam menjalankan tugas

3. Hidup bersih, disiplin, gemar berbagi dan menghargai antar sesama

4. Antusias selalu setiap hari

5. Gembira dalam menjalankan tugas disekolah dan dirumah

6. Indah tutur kata dan penampilan.

7. Aman, nyaman dan menyenangkan

Memiliki gaya kepemimpinan yang berintegritas tinggi, profesional, ramah dan peduli membuat beliau menjadi teladan yang baik bagi guruguru dan juga sangat disayangi anak didik TK, PAUD dan TPA Pertiwi Metro.

\section{c. Peran dan Pendampingan Orang tua di TPA Pertiwi Metro}

Sebagaimanapun baiknya kualitas pendidik dan system pendidikan disekolah akan sia- sia bila tidak ada dukungan dan pendampingan orang tua dirumah, pendidikan keluarga adalah hal yang paling utama dalam menentukan kepribadian anak. Program sekolah yang baik ternyata disambut baik oleh orang tua siswa sehingga ada sinergi antara pihak sekolah dan orang tua. Orang tua merupakan tempat anak mencurahkan isi hatinya, mencari jawab atas rasa keingintahuannya dan menjadi teladan atas berbagai peran di masyarakat. Orang tua yang tidak mengetahui perkembangan anaknya, maka kepribadian anak ikut juga tidak diketahui sehingga orang tua tidak pernah tepat untuk memperlakukan maupun mendidik anaknya ${ }^{13}$. 
Tabel 1. Data tingkat pendidikan dan pekerjaan orang tua/ Wali TPA Petiwi Metro

\begin{tabular}{llll} 
No. & $\begin{array}{l}\text { Tingkat } \\
\text { Pendidikan }\end{array}$ & Jumlah & Keterangan \\
\hline $\mathbf{1}$ & SD & - & - \\
$\mathbf{2}$ & SMP & - & - \\
$\mathbf{3}$ & SMA & - & - \\
$\mathbf{4}$ & S1, S2, S3, Dst. & 24 & -
\end{tabular}

\begin{tabular}{llll} 
No. & Pekerjaan & $\begin{array}{l}\text { Penghasilan/ } \\
\text { bulan }\end{array}$ & Jumlah \\
\hline $\mathbf{1}$ & PNS & 5 Juta- >10 Juta & 12 \\
$\mathbf{2}$ & TNI/ POLRI & 4 Juta-5 Juta & 5 \\
$\mathbf{3}$ & Wiraswasta & 2 Juta- 5 Juta & 5 \\
$\mathbf{4}$ & Karyawan & 1 Juta- 3 Juta & 2 \\
& Swasta & & \\
$\mathbf{5}$ & Buruh & 500Ribu- 1 Juta & - \\
Jumlah & & & $\mathbf{2 4}$
\end{tabular}

Sumber: data sekolah TPA Pertiwi Metro

Dari data diatas dapat dilihat bahwa tingkat pendidikan dan pekerjaan orang tua/ wali siswa di TPA Pertiwi Metro tergolong baik, hal ini juga menunjang bagaimana pendampingan orang tua terhadap anakanak. Terlebih diera digital saat ini orang tua bisa banyak belajar dengan mudah bagaimana cara mendidik anak yang baik, seperti apa cara mengoptimalkan tumbuh kembangnya juga bagaimana menstimulus kecerdasan sosial emosionalnya dengan memberikan perhatian, mengajarkannya bagaimana berinteraksi dengan oranglain dengan baik juga senantiasa mengajarkan anak berbagi dan bertanggungjawab.

Komunikasi antara pihak sekolah dan orang tua menjadi hal yang sangat penting dilakukan, untuk menyamakan persepsi antara programprogram unggulan sekolah dan dukungan dari pihak orantua sehingga apa yang menjadi tujuan pendidikan anak dapat berjalan dengan optimal. 
Komunikasi yang dilakukan disini yaitu dengan mengadakan pertemuan rutin dengan orang tua/wali siswa juga dengan menggunakan aplikasi whats up group (Grup WA) sebagai sarana menjalin kedekatan antara pihak sekolah dan sarana untuk memantau aktifitas dan perkembangan anak di sekolah.

Tabel 2. Jadwal kegiatan satu hari penuh (full day) anak- anak TPA Pertiwi Tahun 2020

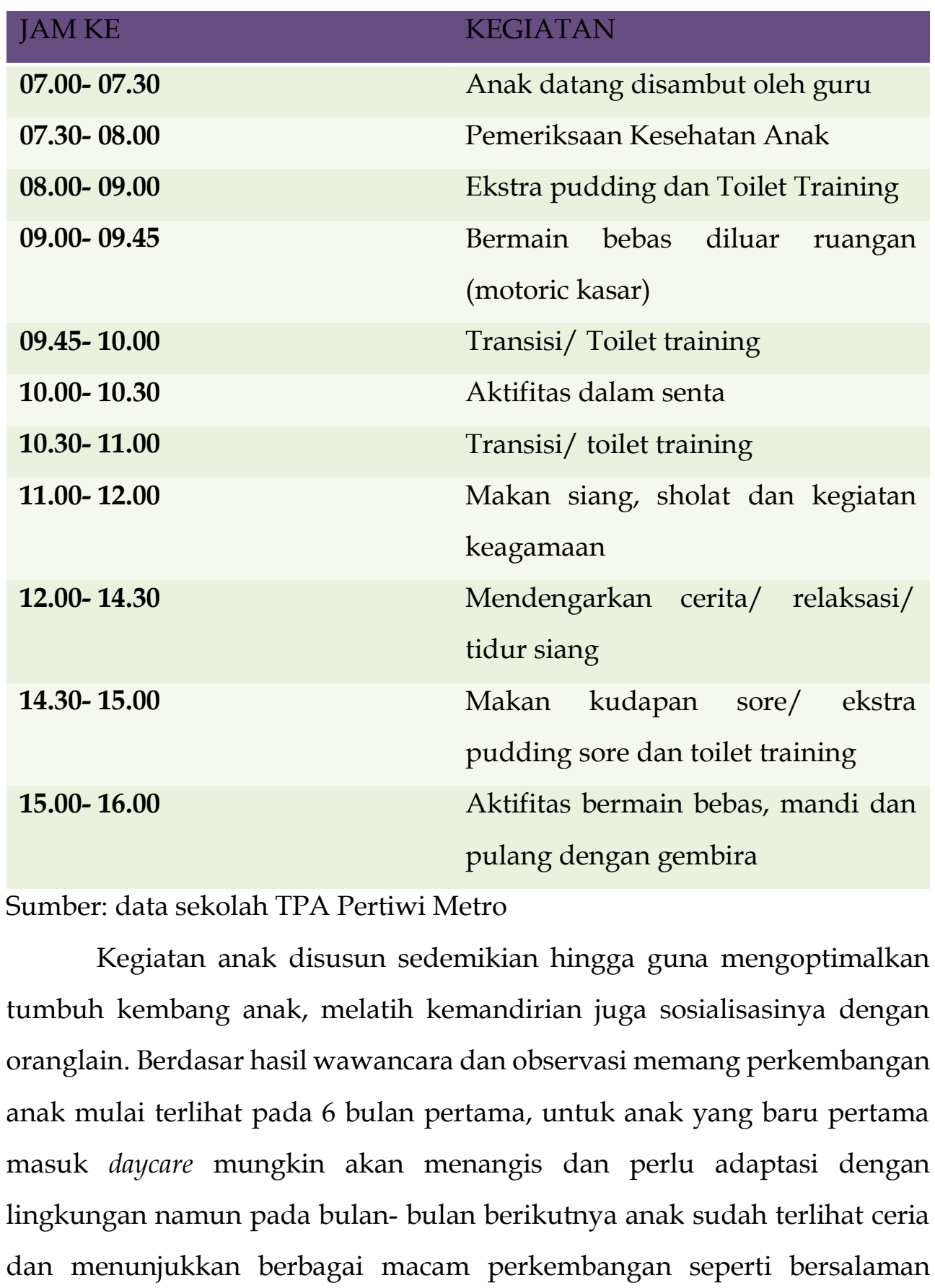


dengan orang yang lebih tua, saling menyayangi dengan sesame teman, bertanggung jawab dengan membereskan mainannya sendiri, menjaga kebersihan lingkungan dengan membuang sampah pada tempatnya.

c. Kendala yang dihadapi dalam proses pendampingan anak di TPA Pertiwi

Kendala yang ditemukan dalam proses pendampingan anak di TPA Pertiwi yang dirasakan oleh dewan guru yaitu ketika tidak ada kerjasama yang baik antara program unggulan yang ditawarkan di sekolah dengan didikan oleh orang tua dirumah, seperti misalnya di TPA anak- anak tidak diperkenannkan bermain $\mathrm{hp} /$ gadget namun di rumah orang tua memberikan keleluasaan bagi anak untuk bermain hp sehingga terbawa ketika di sekolah anak enggan di ajak bermain di luar dan meminta hp pada gurunya. Namun, hal itu masih bisa di atasi oleh guru- guru di TPA yang selalu sabra mendampingi anak- anak, juga selalu ada koordinasi antara pihak sekolah dan orang tua jadi bila terdapat kendala- kendala yang dihadapi dapat dicarikan solusinya bersama.

\section{E. PEMBAHASAN}

Penulis mencoba memaknai TPA (Taman Penitipan Anak) berdasarkan asal katanya menurut KBBI, maka arti kata taman adalah kebun yang ditanami dengan bunga-bunga atau tempat yang indah lagi menyenangkan. Sedangkan arti kata penitipan berasal dari kata titip yang berarti menumpang untuk meletakkan sesuatu. Penitipan itu sendiri memiliki arti proses menaruh suatu barang untuk dijaga atau dirawat, dan anak merupakan keturunan kedua. Maka bila dirangkai menjadi satu kalimat dapat di maknai bahwa Taman Penitipan Anak merupakan sebuah tempat yang menyenangkan untuk menitipkan anak- anak oleh orang tuanya untuk dijaga dan dirawat.

Sejalan dengan hasil penelitian yang sudah dipaparkan bahwasanya di TPA Pertiwi Metro memenuhi standard pemenuhan kebutuhan anak dengan pendampingan guru didukung oleh berbagai kegiatan dan fasilitas yang baik sehingga dapat mengoptimalkan tumbuh kembang anak, disini anak- anak dijaga dan dirawat dengan baik ditempat yang indah dan 
menyenangkan. Hal inilah yang sangat perlu menjadi perhatian orang tua ketika memilih layanan full daycare bagi putera- puterinya yang masih dalam usia balita yang dimungkinkan agar anak- anak tetap pendapat pendampingan dalam mengoptimalkan setiap tahapan tumbuh kembanganya.

\section{F. KESIMPULAN}

Orang tua maupun guru harus lebih banyak mengajak anak bermain permainan yang dapat mengoptimalkan tumbuh kembang anak. Orang tua dan guru dapat melakukannya melalui metode bercerita, bermain peran, dan sebagainya. Ketika orang tua maupun guru memberikan stimulasi dan intervensi yang baik serta didukung oleh lingkungan yang baik pula, maka kecerdasan anak akan berkembang dengan optimal.

TPA Pertiwi Metro merupakan peraih penghargaan juara 1 sekolah Berkarakter tingkat nasional mengusung visi "Mewujudkan sekolah ramah anak, berkarakter, beriman taqwa berbasis lingkungan dan kebhinekaan" dengan beberapa program unggulan yaitu menjunjung tinggi nilai- nilai "BAHAGIA" Bermanfaat dan berguna untuk oranglain, Amanah, kerja keras, tanggungjawab dan ikhlas dalam menjalankan tugas, Hidup bersih, disiplin, gemar berbagi dan menghargai antar sesama, Antusias selalu setiap hari, Gembira dalam menjalankan tugas disekolah dan dirumah, Indah tutur kata dan penampilan, Aman, nyaman dan menyenangkan. Pendampingan kepala sekolah dan guru terhadap perkembangan sosial emosional anak juga sangat dirasakan, mulai dari pagi hari dengan disiplin kepala sekolah dan guru sudah berbaris rapi di depan sekolah tersenyum ramah menyambut kedatangan anak- anak yang juga diantar orang tuanya, inilah yang membuat terjalinnya kedekatan secara emosional anak terhadap gurunya juga guru terhadap orang tuanya sehingga anak betah belajar disekolah dan orang tua tenang menitipkan anaknya untuk dididik di sekolah tersebut.

Kecerdasan dan interaksi sosial emosional anak didik di TPA Pertiwi Metro semakin baik dan meningkat melalui kegiatan- kegiatan yang ada disekolah yaitu dengan melibatkan anak- anak dalam pentas menari, 
taekwondo/karate, renang, mengaji, kegiatan bermain dan belajar didalam kelas juga berkebun, interaksi antar teman dan interaksi dengan para pendidik membuat anak belajar tentang bagaimana sikap saling menghargai, menyayangi, berbagi, mencintai lingkungan dan bertanggung jawab atas apa yang diperbuatnya juga membuat anak lebih percaya diri, karakter inilah yang akan menjadikan anak dimasa yang akan datang.

Beragam fasilitas penunjang juga di hadirkan di TPA Pertiwi Metro, terdapat kolam renang, taman bermain yang luas, mainan edukasi yang beragam juga taman obat keluarga sebagai tempat melakukan kegiatan berkebun bagi anak, UKS, dan kamar tidur yang nyaman. Sehingga menjadikan TPA Pertiwi Metro sebagai solusi pengasuhan anak yang baik bagi bagi orang tua bekerja.

\section{G. DAFTAR PUSTAKA}

Agustian, Ary Ginanjar. ESQ (Emotional Spiritual Quotient: Rahasia Sukses Membangun Kecerdasan Emosi Dan Spiritual. Jakarta: Arga, 2005.

April 1908Brooklyn, Abraham MaslowLahir1, New YorkMeninggal8 Juni 1970CaliforniaKebangsaanAmerikaAlmamaterUniversity of Wisconsin-MadisonDikenal ataspsikologiKarier ilmiahBidangPsikologiInstitusiCornell UniversityBrooklyn CollegeBr, eis UniversityPembimbing doktoralHarry HarlowTerinspirasiAlfred Adler, Kurt Goldstein, Henry MurrayMenginspirasiDouglas McGregor, Colin Wilson, and Abbie Hoffman. "Abraham Maslow - Wikipedia bahasa Indonesia, ensiklopedia bebas." Accessed April 27, 2020. https://id.wikipedia.org/wiki/Abraham_Maslow.

Aslan, Aslan. "Peran Pola Asuh Orang tua Di Era Digital." Jurnal Studia Insania 7, no. 1 (July 7, 2019): 20-34. https://doi.org/10.18592/jsi.v7i1.2269.

Hurlock, Elizabeth B. Psikologi Perkembangan. 5th ed. Jakarta: Erlangga, 1996.

Mayar, Farida. "Perkembangan Sosial Anak Usia Dini sebagai Bibit untuk Masa Depan Bangsa." Al-Ta lim Journal 20, no. 3 (November 21, 2013): 459-64. https://doi.org/10.15548/jt.v20i3.43.

Montessori, Maria. Rahasia Masa Kanak-Kanak. Translated by Ahmad Lintang. Yogyakarta: Pustaka Pelajar, 2016. 
"Norma, Standar, Prosedur, Dan Kriteria (NSPK) Petunjuk Teknis Penyelanggaraan Taman Penitipan Anak," 2013.

Nurmalitasari, Femmi. "Perkembangan Sosial Emosi pada Anak Usia Prasekolah." Buletin Psikologi 23, no. 2 (December 1, 2015): 103-111111. https:// doi.org/10.22146/bpsi.10567.

Setianingrum, Erna. Buku Ajar Tumbuh Kembang Anak Usia 0-12 Tahun. Sidoarjo: Indomedia Pustaka, 2017.

Soenarti, Patmonodewo. Pendidikan Anak Prasekolah. Jakarta: Rineka Cipta, 2003.

Sugiono. Metode Penelitian Kuantitatif Dan Kualitatif. Bandung: Alfabeta, 2012.

Supsiloani, Supsiloani Supsiloani, Puspitawati Puspitawati Puspitawati, and Noviy Hasanah. "Eksistensi Taman Penitipan Anak dan Manfaatnya bagi Ibu Rumah Tangga yang Bekerja (Studi Kasus di TPA Dharma Asih Kota Medan)." JUPIIS: JURNAL PENDIDIKAN ILMU-ILMU SOSIAL 7, no. 2 (2015): $119-24$. https://doi.org/10.24114/jupiis.v7i2.3117.

"The Golden Age | SpringerLink." Accessed April 27, 2020. https://link.springer.com/chapter/10.1007\%2F978-3-319-04840$6 \_5$. 